\title{
Experimental Verification of the Use of Metal Filled Via Hole Fences for Crosstalk Control of Microstrip Lines in LTCC Packages
}

\author{
George E. Ponchak, Donghoon Chun, Jong-Gwan Yook, and Linda P. B. Katehi \\ Paper Submitted to the \\ IEEE Transactions on Advanced Packaging
}

Corresponding author:

George E. Ponchak

NASA Glenn Research Center

21000 Brookpark Rd., MS 54/5

Cleveland, $\mathrm{OH} 44135$

Tel: $216-433-3504$

Fax: 216-433-8705

Email: george.ponchak@grc.nasa.gov

Donghoon Chun

University of Michigan

1301 Beal Ave.

3240 EECS Building

Ann Arbor, MI 48109-2122

Jong-Gwan Yook

Dept. of Information and Communications

Kwang-Ju Institute of Science and Technology

Kwang-Ju, Book-Ku

O-ryong-dong, Korea 500-712

Linda P. B. Katehi

University of Michigan

1301 Beal Avenue

3240 EECS Building

Ann Arbor, MI 48109-2122 


\title{
Experimental Verification of the Use of Metal Filled Via Hole Fences for Crosstalk Control of Microstrip Lines in LTCC Packages
}

\author{
George E. Ponchak, Donghoon Chun, Jong-Gwan Yook, and Linda P. B. Katehi
}

\begin{abstract}
Coupling between microstrip lines in dense RF packages is a common problem that degrades circuit performance. Prior 3DFEM electromagnetic simulations have shown that metal filled via hole fences between two adjacent microstrip lines actually increases coupling between the lines; however, if the top of the via posts are connected by a metal strip, coupling is reduced. In this paper, experimental verification of the 3D-FEM simulations is demonstrated for commercially fabricated LTCC packages.
\end{abstract}

Index Terms- microstrip, coupling, crosstalk, microwave transmission lines

\section{INTRODUCTION}

RF systems being planned today integrate more functions in smaller packages that must cost less than those currently being used do. Although several packaging technologies have been proposed to meet these goals [1-5], Low Temperature Cofired Ceramic (LTCC) may be the ideal packaging technology. The material used in LTCC has a moderate relative dielectric constant, $\varepsilon_{7}$, between 4 and 8 , which permits wider microwave transmission lines and has lower conductor loss than circuits on $\mathrm{Si}, \mathrm{GaAs}$, and Alumina. It also has a low loss tangent of 0.002 at $10 \mathrm{GHz}$, which results in low dielectric attenuation. Packages are built with multiple layers of 0.1 to $0.15 \mathrm{~mm}$ thick ceramic layers with metal lines permitted on each layer and metal filled via holes interconnecting each layer [2,6]. Therefore, dense packages with RF integrated circuits, digital integrated circuits, bias lines, and interconnect lines may be built.

However, dense packages with closely spaced interconnect lines are prone to coupling or crosstalk that may severely degrade circuit performance. Microstrip transmission lines radiate at discontinuities [7], and this radiated power may couple to other microstrip lines. In addition, parallel microstrip lines couple energy between each other [8]. To help alleviate this coupling, metal filled via holes are often used to create Faraday cages that isolate sections of the package from each other [9-12]. Three Dimensional-Finite Element Method (3D-FEM) electromagnetic modeling of parallel microstrip lines separated by metal filled via hole fences has shown that the fences do not reduce coupling, but if the top of the via posts are connected with a metal strip, coupling is significantly reduced $[13,14]$.

In this paper, commercial LTCC process and design layout rules are used to experimentally verify the 3D-FEM electromagnetic modeling results. Test circuits are built by a commercial vendor and characterized over the frequency band of 2 to $40 \mathrm{GHz}$. The propagation characteristics of microstrip lines as a function of the via fence geometry is presented first. Then, coupling between parallel microstrip lines is presented as a function of frequency and the via fence geometry. Throughout the paper, the results are qualitatively compared to the 3D-FEM results.

\section{Circuit Fabrication and Design}

Manuscript received XXX; revised XXX. This work was supported by NASA Glenn Research Center, the University of Michigan Center for Parallel Computing which is partially funded by NSF grant CDA-92-14296 and Ford Motor Company, and Dielectric Laboratories Inc. George E. Ponchak is with the Electron Device Technology Branch, NASA Glenn Research Center, Cleveland, OH 44135 USA. Donghoon Chun and Linda P. B. Katehi are with the Department of Electrical Engineering and Computer Science, University of Michigan, Ann Arbor, M 48109-2122, USA. Jong-Gwan Yook is now with the Dept. of Information and Communications, Kwang-Ju Institute of Science and Technology, Kwang-Ju, Book-ku, O-ryong-dong, Korea, $500-712$ 
Test circuits are fabricated using commercial LTCC fabrication process and layout rules [15]. The ceramic material is mounted on a $\mathrm{Cu} / \mathrm{Mo} / \mathrm{Cu}$ metal core that is thermal coefficient of expansion (TCE) matched to the LTCC dielectric, Si, and $\mathrm{GaAs}$. A single layer of ceramic tape is used for the microstrip substrate. This substrate is 0.005 inch $(127 \mu \mathrm{m})$ thick, has a relative dielectric constant, $\varepsilon_{\mathrm{T}}$, of 5.67 at $12.5 \mathrm{GHz}$, and a volume resistivity of $5 \times 10^{15} \Omega-\mathrm{cm}$. Via holes are 0.008 inch $(203 \mu \mathrm{m})$ in diameter and have a minimum via to via spacing of 0.024 inch $(609 \mu \mathrm{m})$. All metal traces, including the microstrip lines, have a minimum conductor width and conductor to conductor line spacing of $0.008 \mathrm{inch}(203 \mu \mathrm{m})$. The metal filled vias and lines are $\mathrm{Ag}$, with the lines coated with $\mathrm{Ni} / \mathrm{Au}$. Total microstrip metal thickness is measured to be $15 \mu \mathrm{m}$ with a variation (surface roughness) of $\pm 4 \mu \mathrm{m}$.

Microstrip lines are designed with a strip width, W, of 0.008 inch $(203 \mu \mathrm{m})$, which yields a theoretical characteristic impedance of $50 \Omega$. Referring to Figure 1 , microstrips with via to line spacing, $S$, of $0.012,0.016$, and 0.020 inch $(304,406$, and $508 \mu \mathrm{m})$ and via to via spacing, $G$, of 0.024 and 0.032 inch $(610$ and $813 \mu \mathrm{m})$ are fabricated both with and without a strip connecting the tops of the via holes. To maintain the same descriptions as [14], $S$ and $G$ are normalized to the substrate thickness, $h$, throughout the paper. Therefore, microstrip lines with $S / h$ of $2.4,3.2$, and 4 and $G / h$ of 4.8 and 6.4 are fabricated. To measure the coupling between adjacent microstrip lines, two sets of circuits are characterized. The first, which is shown schematically in Figure 2a, consists of two short circuit terminated microstrip lines adjacent to each other. Port 1 is the input port and the coupled power is measured at Port 3. Because a standing wave is established on the short circuit terminated lines, coupling measured with this technique is $6 \mathrm{~dB}$ higher than the actual coupling. The second set is shown schematically in Figure $2 \mathrm{~b}$ and consists of a four port circuit that enables the measurement of the forward and backward coupling, $S_{13}$ and $S_{14}$ respectively. Via fences with and without connecting strips are placed between the microstrip lines to characterize their effectiveness in reducing coupling. Microstrip line to line spacing, $\mathrm{D} / \mathrm{h}$, of 4.8 and 6.4 are characterized, and in both sets of circuits, the coupling length, $\mathrm{L}$, is 0.280 inch $(0.7112 \mathrm{~cm})$.

Measurements are made on a vector network analyzer from 2 to $40 \mathrm{GHz}$. A Thru/Reflect/Line (TRL) calibration is implemented with MULTICAL, a TRL software program, using two delay lines of 1750 and $5000 \mu \mathrm{m}$ and a short circuit reflect fabricated on the same substrate as the circuits. The attenuation constant and effective permittivity, $\varepsilon_{\text {eff, }}$ of the microstrip line is determined by the TRL calibration routine [16]. To improve accuracy, three sets of circuit boards were fabricated and characterized. The average of those three measurements is presented in this paper.

\section{Results}

First, the propagation characteristics of the microstrip lines as a function of the via fence geometry is measured. Figure 3 shows the attenuation, $\alpha$, in $\mathrm{dB} / \mathrm{cm}$ of a microstrip line with no via fence and a microstrip line with $\mathrm{G} / \mathrm{h}=4.8$ and $\mathrm{S} / \mathrm{h}=2.4,3.2$, and 4. It is seen that each line has the same attenuation characteristics. Moreover, the other microstrip lines also have the same qualitative characteristics with respect to frequency with no resonances or irregularities. The microstrip lines are designed with a maximum separation between the via fences, $2 \mathrm{~S}+\mathrm{W}$, that does not support quasi-rectangular waveguide type modes below 50 GHz. If the via fences are too far apart and higher order modes are present, the propagation characteristics are severely degraded. Below $20 \mathrm{GHz}$, it is noticed that the attenuation has a $\mathrm{f}^{0.5}$ frequency dependence, which is expected when conductor loss dominates; however, there is an inflection point at $20 \mathrm{GHz}$ where the frequency dependence becomes nearly linear. This same increase in attenuation above $20 \mathrm{GHz}$ for $50 \Omega$ microstrip lines on LTCC substrates has been reported previously [17]. Therefore, it is not believed to be due to measurement error. Also, because the frequency characteristic of the measured attenuation is independent of the via geometry, the higher attenuation is not due to the via fences. 
Since each line has the same frequency dependence, the attenuation as a function of the via geometry may be summarized in a single illustration. This is done in Figure 4, which shows $\alpha$ as a function of $\mathrm{S} / \mathrm{h}$ and $\mathrm{G} / \mathrm{h}$ at $10 \mathrm{GHz}$. It is seen that $\alpha$ is lower when microstrip is surrounded by a via fence without the connecting strip on top of the via posts; however, when the connecting strip is added, $\alpha$ is higher for small $\mathrm{S} / \mathrm{h}$. Also, for all line geometry, $\alpha$ decreases as $\mathrm{S} / \mathrm{h}$ increases. The attenuation dependence on $\mathrm{S} / \mathrm{h}$ is in agreement with the theoretical results [14], but the theoretical attenuation, which only includes radiation loss, decreases when the connecting strip is added to the via fence, which is not observed in the measured results. Since significant electric fields terminate on the connecting strip when $\mathrm{S} / \mathrm{h}$ is small, the propagating mode is similar to a coplanar waveguide (CPW) mode. CPW has higher conductor loss than similarly sized microstrip lines [18]. Therefore, the higher attenuation seen here is attributed to conductor loss.

The measured effective permittivity for each microstrip line is nearly independent of frequency, with a maximum variation of 2.5 percent from 2 to $40 \mathrm{GHz}$. Therefore, the measured $\varepsilon_{\mathrm{off}}$ is summarized as a function of the via fence geometry in Figure 5. First, notice that $\varepsilon_{\text {eff }}$ of the microstrip line with no vias is 4.13 , which is within 2 percent of the predicted value of 4.08 [18]. Via fences, regardless of their geometry, lower $\varepsilon_{\text {eff }}$ compared to a microstrip line without a via fence. For example, at $\mathrm{S} / \mathrm{h}=3.2$, via fences without a strip lower $\varepsilon_{\text {eff }}$ by 3.6 percent and via fences with a connecting strip lower $\varepsilon_{\mathrm{eff}}$ by 13.3 percent. Furthermore, $\varepsilon_{\text {eff }}$ decreases as $S / h$ increases. While via fences lower $\varepsilon_{\mathrm{eff}}$ because the microstrip line and fence structure supports CPW modes that have higher electric field concentration in the air, and thus, lower $\varepsilon_{\mathrm{efr}}$. The $\mathrm{S} / \mathrm{h}$ dependence is not expected though. Theoretical $\varepsilon_{\mathrm{eff}}[14]$ has the opposite dependence on $\mathrm{S} / \mathrm{h}$ than the measured $\varepsilon_{\mathrm{eff}}$ shown in Figure 5 . Intuitively, we expect that the theoretical results are correct since the propagation characteristics should approach the characteristics of the line with no via fence as $\mathrm{S} / \mathrm{h}$ increases, which the theoretical results do. Measurement error does not explain this disagreement since the average standard deviation, $\sigma$, for the points shown in Figure 5 is 0.164 with $\sigma_{\max }=0.31$ and $\sigma_{\min }=0.046$. Furthermore, multiple measurements on a single sample have an average $\sigma$ of only 0.02 .

Figure 6 shows the measured coupling between two parallel microstrip lines. The continuous lines are the measured forward coupling, $S_{13}$, from the four port circuit shown in Figure $2 b$, and the discreet points are the measured coupling from the two port circuit shown in Figure 2a. The two sets of measurements are in excellent agreement, which indicates the accuracy of the coupling results. For $\mathrm{D} / \mathrm{h}=4.8$ and 6.4 , it is seen that the addition of a via fence does not reduce the forward coupling, and in fact, $S_{13}$ is one to two $d B$ higher with the via fence compared to the microstrip without a via fence. Forward coupling is reduced by approximately $5 \mathrm{~dB}$ and $3 \mathrm{~dB}$ for $\mathrm{D} / \mathrm{h}=4.8$ and 6.4 respectively when a 0.008 inch metal strip connects the tops of the via posts. All of these results are in agreement with theoretical results [14]. Notice that microstrip lines with $\mathrm{D} / \mathrm{h}=4.8$ and a via fence with connecting strip have lower coupling than microstrip lines spaced 33 percent further apart, $D / h=6.4$, without via fences. This decrease in coupling enables higher packing densities in RF packages. The measured maximum backward coupling, $\mathrm{S}_{14}$, is $30 \mathrm{~dB}$, or approximately $5 \mathrm{~dB}$ lower than the forward coupling. Moreover, there is no measurable dependence of $\mathrm{S}_{14}$ on the via fence geometry.

\section{Conclusions}

Using commercial Low Temperature Cofired Ceramic (LTCC) packaging technology, the use of metal filled via fences to reduce the coupling between parallel microstrip lines is experimentally demonstrated. It is shown that a metal filled via fence does not reduce coupling between microstrip lines; however, if the tops of the metal filled posts are connected with a metal strip, the coupling is reduced by $5 \mathrm{~dB}$. These coupling results are in agreement with the theoretical results published earlier and enable 
denser RF packages. The measured attenuation for microstrips surrounded by via fences with a connecting strip is slightly higher than isolated microstrip lines due to higher conductor loss associated with the CPW mode.

\section{References}

[1] R. W. Johnson, R. K. F. Teng, and J. W. Balde eds., Multichip Modules Systems Advantages, Major Constructions, and Material Technologies, New York, NY: IEEE Press, 1991.

[2] R. L. Brown, P. W. Polinski, and A, S. Shaikh, "Manufacturing of microwave modules using low-temperature cofired ceramics," in 1994 IEEE MTT-S Int. Microwave Symp. Dig., 1994, pp. 1727-1730.

[3] H. Sakai, Y. Ota, K. Inoue, T. Yoshida, K. Takahashi, S. Fujita, and M. Sagawa, "A novel millimeter-wave IC on Si substrate using flip-chip bonding technology," in 1994 IEEE MTT-S Int. Microwave Symp. Dig., 1994, pp. 1763-1766.

[4] G. White, E. Perfecto, D. McHerron, T. DeMercurio, T. Redmond, and M. Norcott, "Large format fabrication-a practical approach to low cost MCM-D," IEEE Trans. on Components, Packaging, and Manufacturing Tech.-Part B, Vol. 18, No. I, pp. 37-41, Feb. 1995.

[5] R. A. Fillion, R. J. Wojnarowski, T. B. Gorcyzca, E. J. Wildi, and H. S. Cole, "Development of a plastic encapsulated multichip technology for high volume, low cost commercial electronics," IEEE Trans. on Components, Packaging, and Manufacturing Tech.-Part B, Vol. 18, No. 1, pp. 59-65, Feb. 1995.

[6] R. W. Johnson, ed., Modular Series in Hybrid Microelectronics, Reston, VA: International Society for Hybrid Microelectronics, 1991.

[7] N. G. Alexopoulos and S. -C. Wu, "Frequency-independent equivalent circuit model for microstrip open-end and gap discontinuities," IEEE Trans. Microwave Theory Tech., Vol. 42, No. 7, pp. 1268-1272, July 1994.

[8] R. E. Collin, Foundations for Microwave Engineering, pp. 164-175, New York, NY: McGraw-Hill, Inc., 1992.

[9] J. W. Gipprich, "EM modeling of via wall structures for high isolation stripline," in Digest for Workshop WWFC, Interconnect and Packaging Technologies and Issues, IEEE Int. Microwave Symp., San Diego, CA, pp. 78-114, June 1994.

[10] J. Gipprich, C. Wilson, and D. Stevens, "Multilayered 3-D packaging issues," in Digest for Workshop WFC, Interconnects and Packaging for RF Wireless Communications Systems, IEEE Int. Microwave Symp., Denver, CO, June 8-13, 1997.

[11]J. Gipprich and D. Stevens, "Isolation characteristics of via structures in high density stripline packages," in Digest for Workshop WME, Multilayer Microwave Circuits, IEEE Int. Microwave Symp., Baltimore, MD, June 7-12, 1998.

[12]M. - K. Kim, "Crosstalk control for microstrip circuits in PCBs at microwave frequencies," in Proc. of Int. Symp. On Electromagnetic Compatibility, 1995, pp. 459-464.

[13] G. E. Ponchak, D. Chen, J.- G. Yook, and L. P. B. Katehi, "Filled via hole fences for crosstalk control of microstrip lines in LTCC packages," in 3rd International Wireless Communications Conference (WCC '98) Digest, San Diego, CA, Nov. 1-3, 1998, pp. 96-100. Also in Proc. IMAPS 199831 st Int. Symp. on Microelectronics, San Diego, CA, Nov. 2-4, 1998.

[14] G. E. Ponchak, D. Chun, J.-G. Yook, and L. P. B. Katehi, "The use of metal filled via holes for improving isolation in LTCC RF and wireless multichip packages," accepted for publication in IEEE Trans. Components, Packaging, and Manufacturing Tech. -Part B.

[15]Dielectric Laboratories Inc., DiPak Design Guidelines.

[16]D. F. Williams, R. B. Marks, and A. Davidson, "Comparison of on-wafer calibrations," $38^{\text {th }}$ ARFTG Conf. Dig., San Diego, CA, Dec. 5-6, 1991.

[17]Dielectric Laboratories Inc., DiPak Millimeter Wave Package DC-40 GHz product description. 
[18]I. Bahl and P. Bhartia, Microwave Solid State Circuit Design, John Wiley \& Sons, New York, New York, 1988. 


\section{List of Figures}

1. (a) Top view and (b) cross section cut schematic of microstrip line surrounded by a via fence.

2. Schematic of test circuits for measuring coupling between two microstrip lines. (a) is a two port circuit and (b) is a four port circuit.

3. Measured attenuation in $\mathrm{dB} / \mathrm{cm}$ as a function of frequency of a microstrip line with no vias and microstrip lines with via fences with $\mathrm{G} / \mathrm{h}=4.8$ and $\mathrm{S} / \mathrm{h}=2.4,3.2$, and 4 .

4. Measured attenuation $(\mathrm{dB} / \mathrm{cm})$ of microstrip lines as a function of the via fence geometry.

5. Measured effective permittivity of microstrip lines as a function of the via fence geometry.

6. Measured coupling between two microstrip lines with (a) $\mathrm{D} / \mathrm{h}=4.8$ and (b) 6.4 as a function of frequency and the via fence geometry. Continuous lines are measured from the four port circuit in Figure $2 \mathrm{~b}$ and the discrete points are measured from the two port circuit in Figure $2 \mathrm{a}$. 


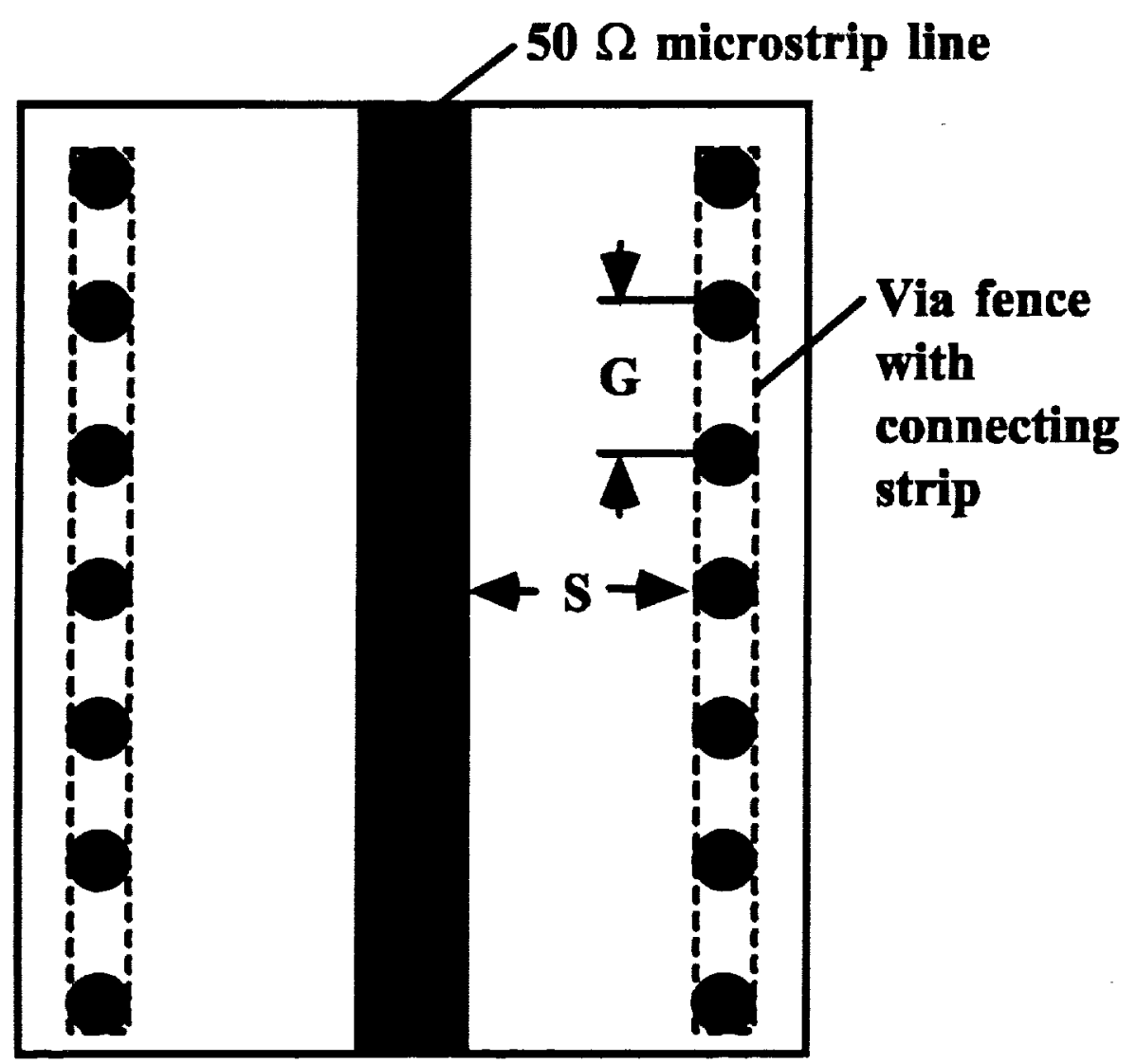

(a)

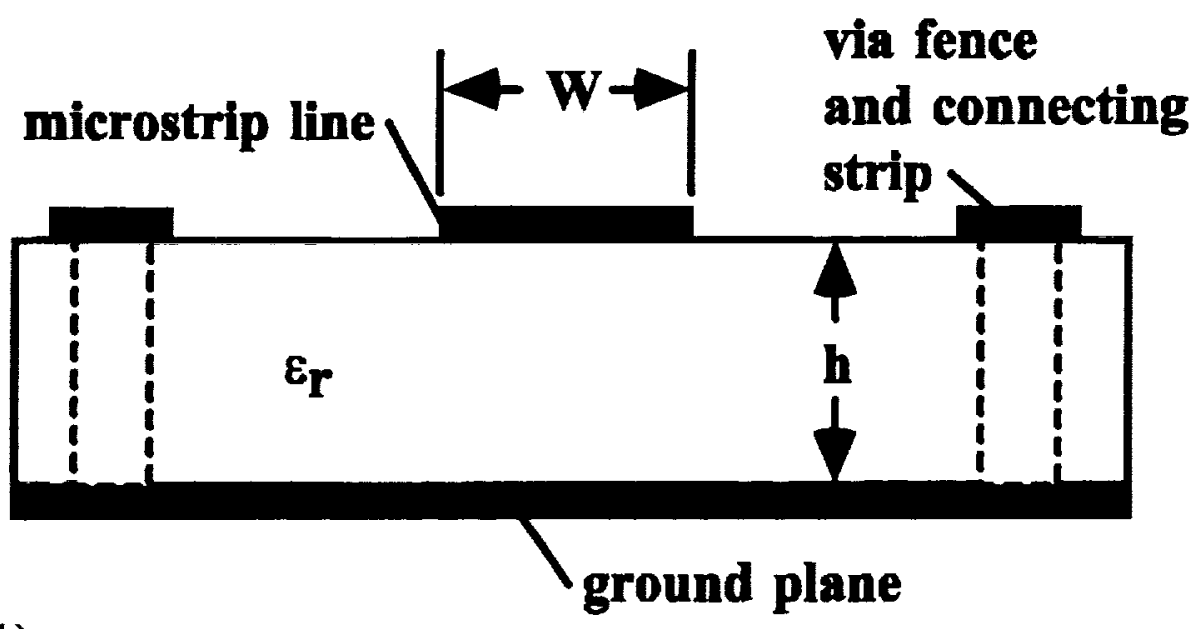

(b)

Figure 1: (a) Top view and (b) cross section cut schematic of microstrip line surrounded by a via fence. 


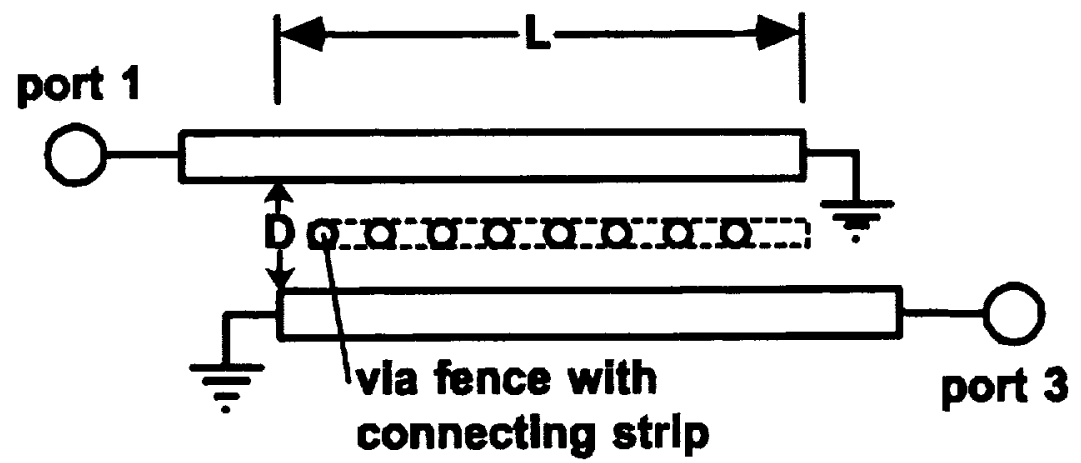

(a)

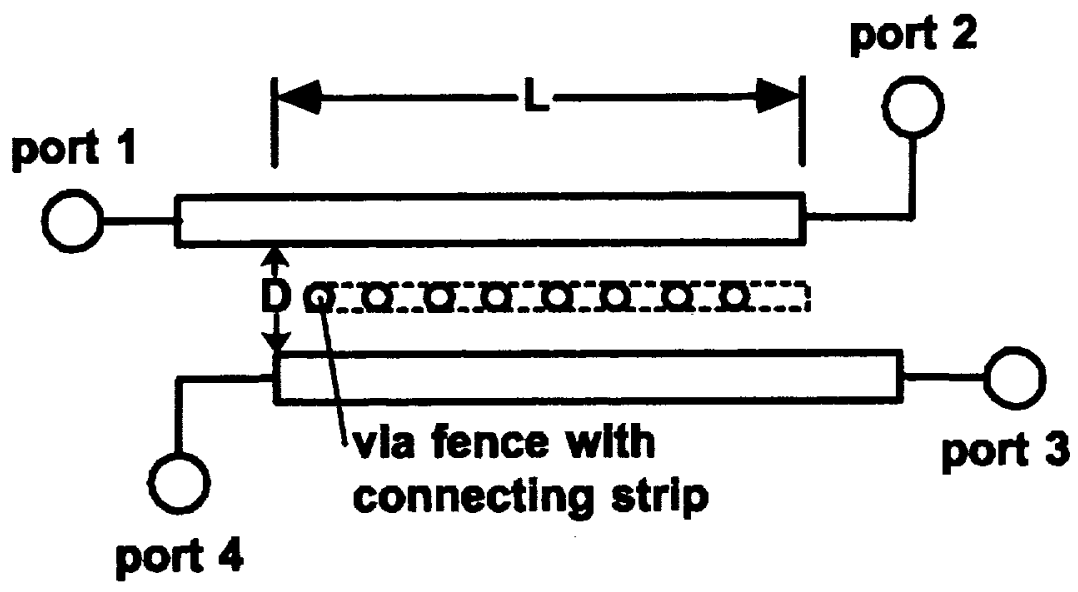

(b)

Figure 2: Schematic of test circuits for measuring coupling between two microstrip lines. (a) is a two port circuit and (b) is a four port circuit. 


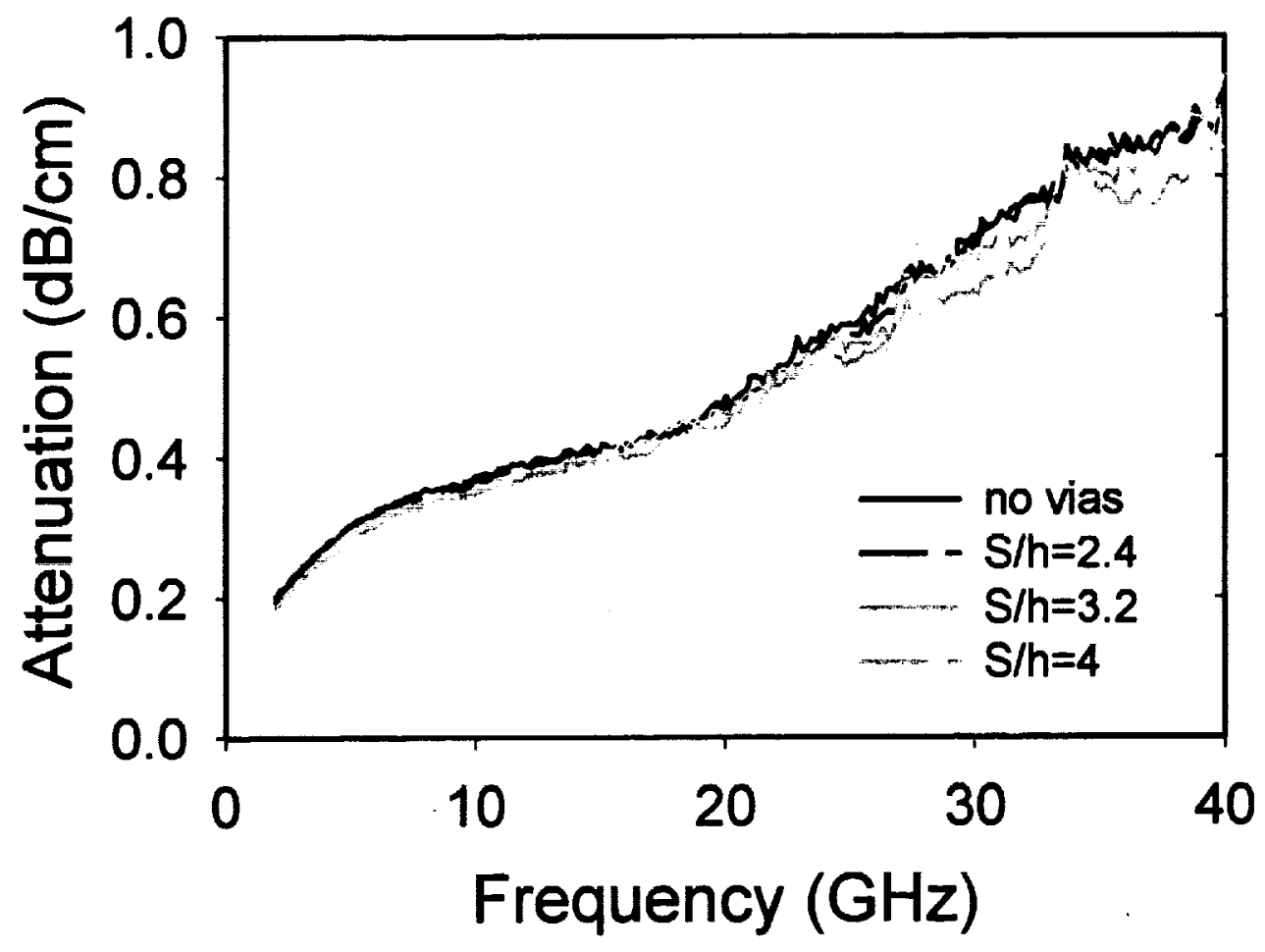

Figure 3: Measured attenuation in $\mathrm{dB} / \mathrm{cm}$ as a function of frequency of a microstrip line with no vias and microstrip lines with via fences with $G / h=4.8$ and $S / h=2.4,3.2$, and 4 . 


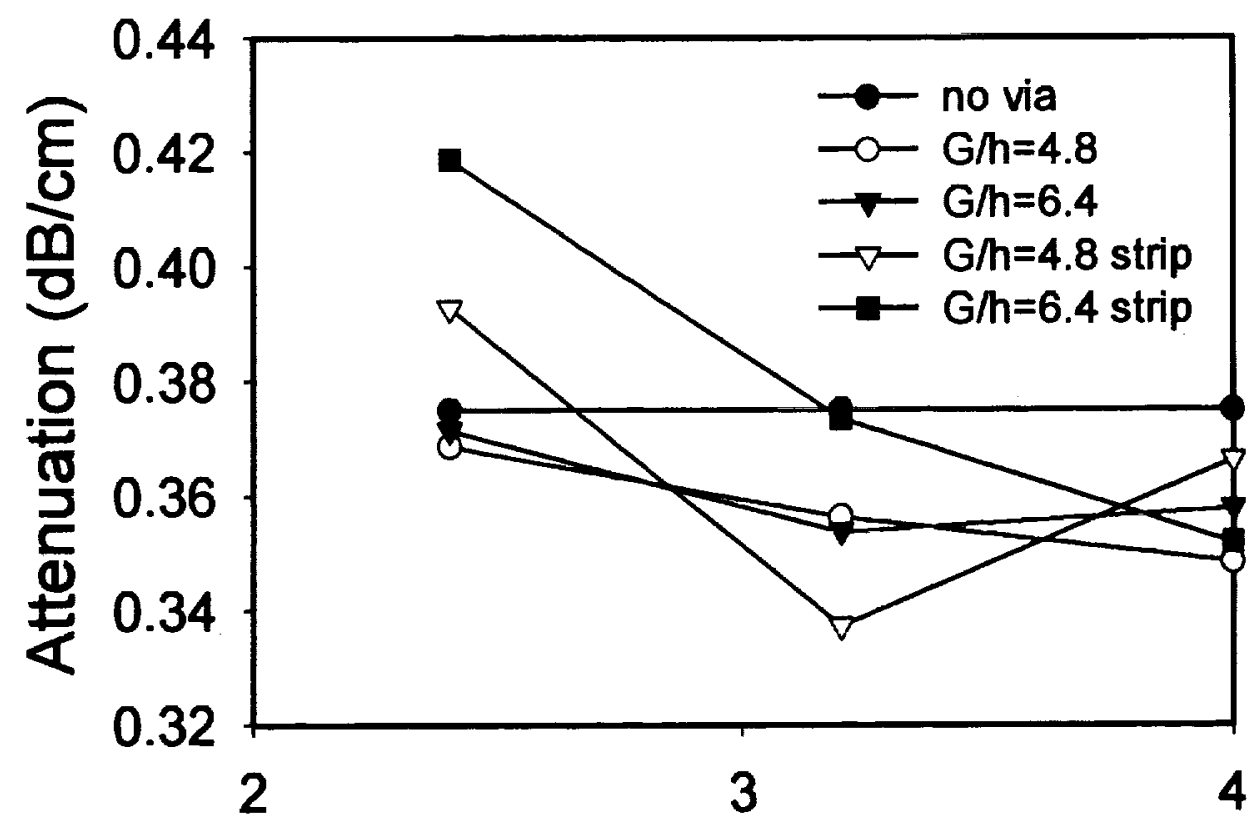

Ratio of via/line spacing to substrate thickness, $S / h$

Figure 4: Measured attenuation $(\mathrm{dB} / \mathrm{cm})$ of microstrip lines as a function of the vis fence geometry. 


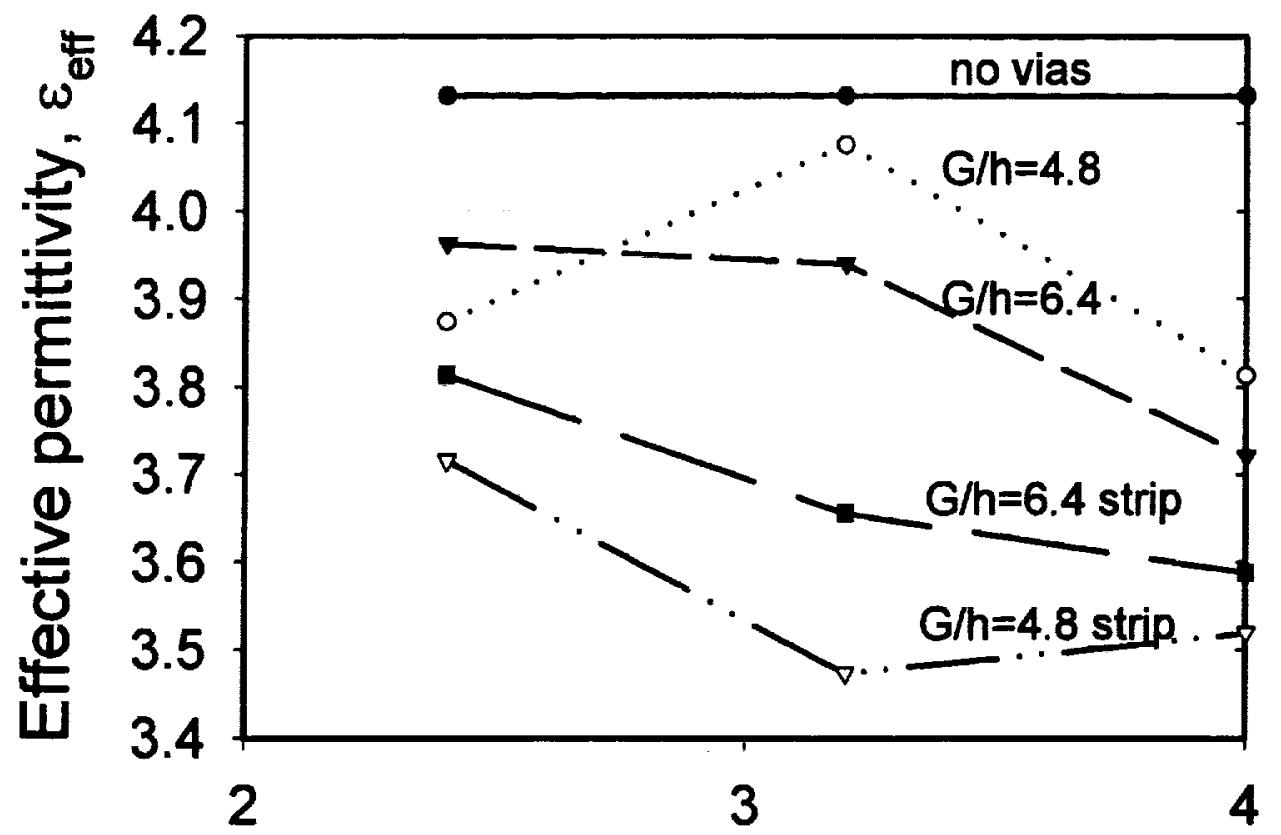

Ratio of via/line spacing to substrate thickness, S/h

Figure 5: Measured effective permittivity of microstrip lines as a function of the via fence geometry. 


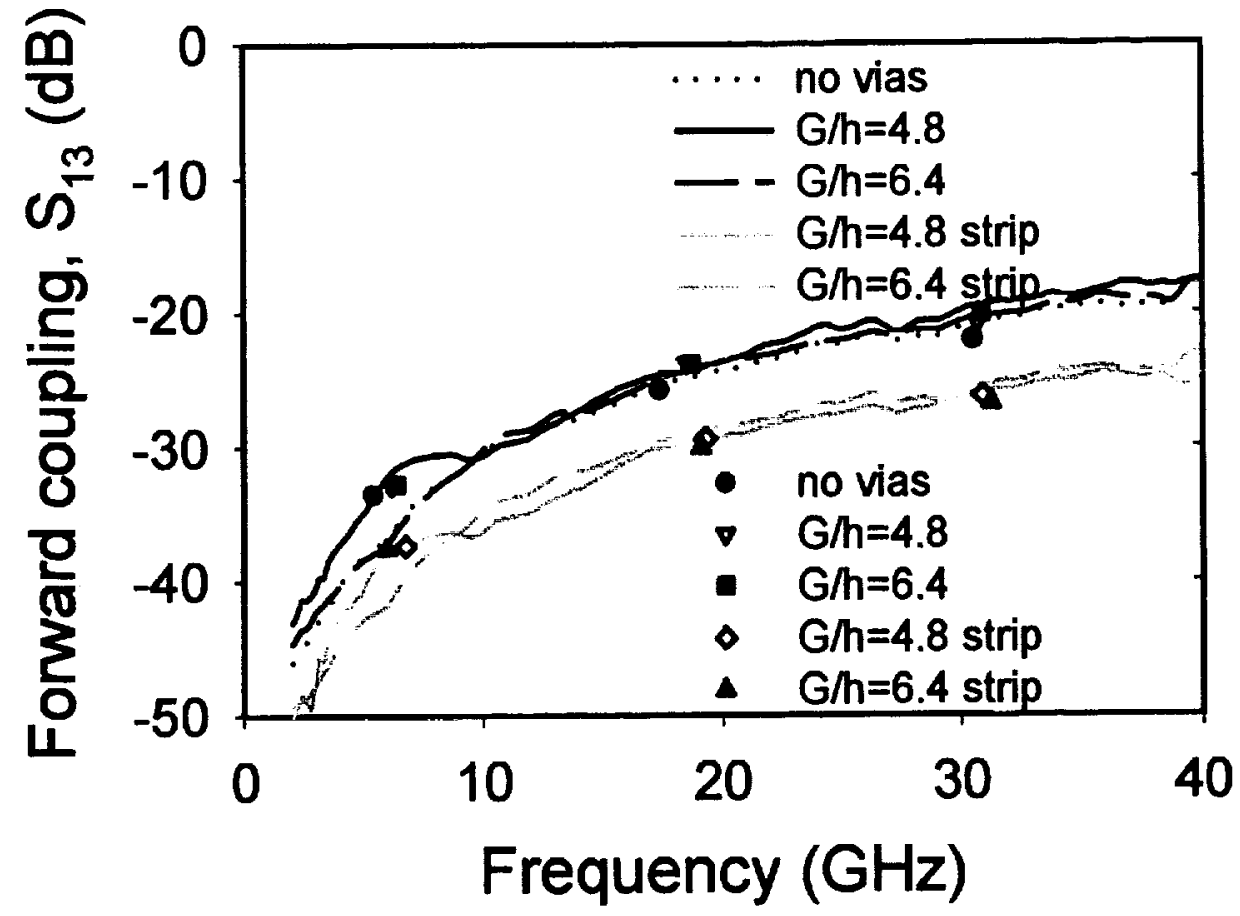

(a)

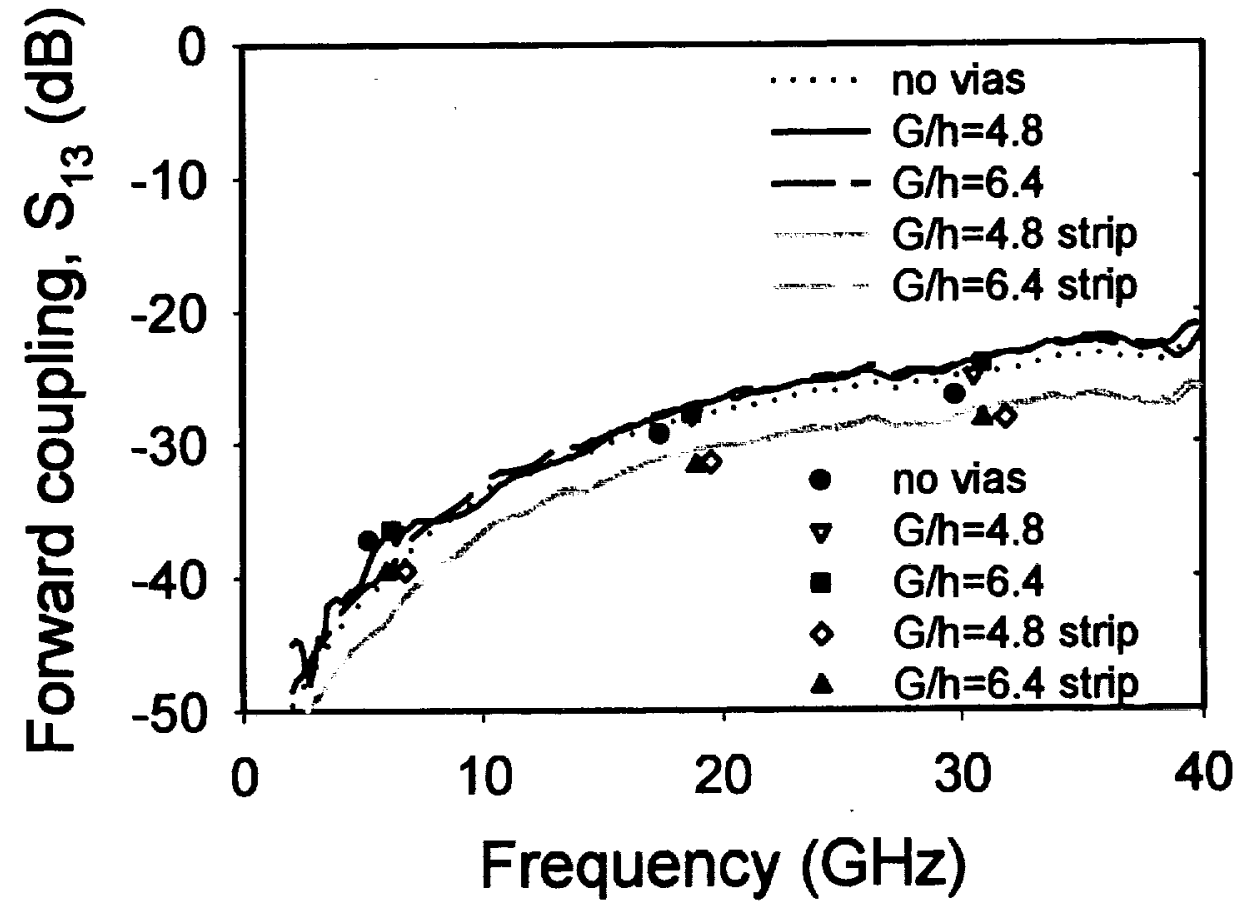

(b)

Figure 6: Measured coupling between two microstrip lines with (a) $D / h=4.8$ and (b) 6.4 as a function of frequency and the via fence geometry. Continuous lines are measured from the four port circuit in Figure $2 b$ and the discrete points are measured from the two port circuit in Figure $2 \mathrm{a}$. 


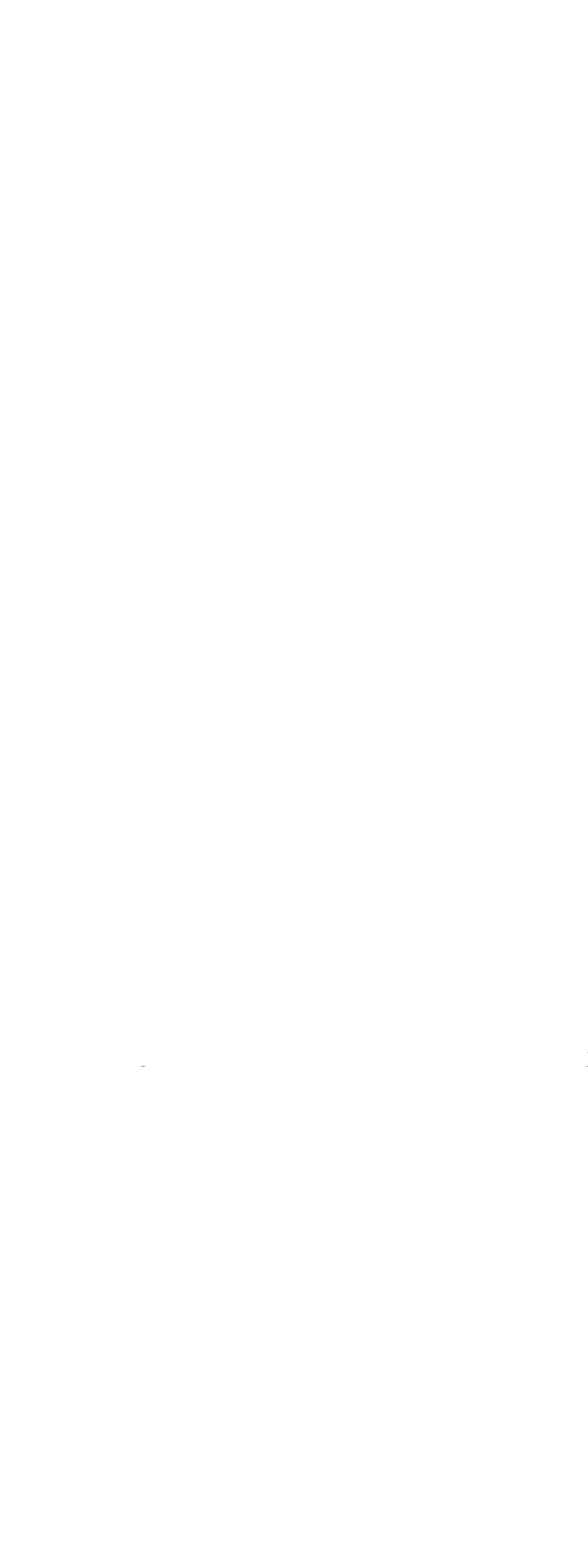

